\title{
Deglutinação e aglutinação do artigo como fonte de neologismos em Português
}

\section{Deglutination and Agglutination of the Article as a Source of Neologisms in Portuguese}

PrzemysŁaw DęBowiak [przemyslaw.debowiak@uj.edu.pl]

Uniwersytet Jagielloński w Krakowie, Polónia

\begin{abstract}
RESUMO
No presente trabalho, baseado no léxico da língua portuguesa, examina-se o processo que consistiu numa reinterpretação, ao nível morfológico, dos sintagmas nominais, constituídos por um substantivo precedido ou não de um artigo. Esta reanálise das fronteiras entre palavras, chamada deglutinação ou aglutinação do artigo, deu origem a neologismos que ora acabaram por entrar no léxico, substituindo as antigas formas que eram mais próximas dos seus étimos, ora funcionam ao lado das antigas formas como os seus sinónimos ou com aceções diferentes (alimentando desse modo o grupo de palavras divergentes).
\end{abstract}

\section{Palavras-chave}

morfologia derivacional; português; deglutinação; aglutinação; artigo

\begin{abstract}
In this paper, based on the vocabulary of the Portuguese language, the process which consisted in reinterpretation, on the morphological level, of nominal syntagmas formed by a noun preceded or not by an article, is examined. This reanalysis of borders between words, called deglutination or agglutination of the article, originated neologisms (new words) which have eventually entered the vocabulary, thus replacing the ancient forms that were closer to their etymons, or exist next to the ancient forms as their synonyms or with different meanings (and thereby aliment the group of doublets).
\end{abstract}

\section{KEYWORDS}

derivational morphology; Portuguese; deglutination; agglutination; article

RECEBIDO 2016-11-07; ACEITE 2017-01-09 


\section{Introdução}

$\mathrm{Na}$ área da morfologia derivacional, a tradição gramatical portuguesa distingue alguns processos, uns mais produtivos do que outros, tanto na diacronia como na sincronia. Trata-se sobretudo da derivação afixal (sufixal e prefixal), derivação regressiva, derivação imprópria e composição (por aglutinação e justaposição).

A composição por aglutinação, consistindo numa fusão de palavras ou sintagmas num só vocábulo através de uma lexicalização semântica e formal completa (cf. Villalva 2003: 980), ocorreu em vários idiomas, o que se comprova através do estudo da história do vocabulário. Deu-se, por exemplo, tanto na passagem do latim para as línguas românicas, como já nestas línguas: lat. *bis coctu- 'cozido duas vezes' > pt. biscoito / esp. bizcocho / fr. biscuit / it. biscotto; lat. male habitu- 'em mau estado' > fr. malade / it. malato 'doente’; lat. ${ }^{\star}$ Mercuris dies 'dia de Mercúrio' $>$ fr. mercredi / it. mercoledi 'quarta-feira'; fr. au jour d'hui 'no dia de hoje'> aujourd'hui 'hoje'; rom. astă $z i$ 'este dia' > astăzi 'hoje’.

Além dos processos acima enumerados, existe outro semelhante que constitui uma fonte de neologismos ${ }^{1}$. Estamos a aludir a uma reanálise das fronteiras entre palavras que não tem lugar próprio na referida classificação, mas que podia ser encarada como um tipo de composição por aglutinação. Mais especificamente, trata-se de uma reinterpretação, ao nível morfológico, dos sintagmas nominais, constituídos por um substantivo precedido ou não de um artigo. Desta reinterpretação resultou uma nova segmentação das sequências, dando assim origem a neologismos que ora acabaram por entrar no léxico, substituindo as antigas formas que eram mais próximas dos seus étimos, ora funcionam ao lado das antigas formas como os seus sinónimos ou com aceções diferentes (alimentando desse modo o grupo das chamadas palavras divergentes).

É precisamente este processo que pretendemos examinar mais detalhadamente no presente trabalho, com base no léxico da língua portuguesa.

O fenómeno em questão está intimamente relacionado com as mudanças fonéticas que se documentam no desenvolvimento de qualquer língua: acréscimo e desaparecimento do som no início de uma palavra ou outro segmento, ou seja, a prótese e a aférese. Na língua portuguesa há muitos vocábulos que resultam desses processos, dos quais a prótese ocorreu mais frequentemente. Como exemplos, citem-se dois casos:

- /e/- protético que aparece no início de palavras começando com a sequência /s/- + consoante: lat. spīca- > pt. espiga; lat. stāre > pt. estar; lat. scūtu- > pt. escudo (mesmo que posteriormente deixe de ser pronunciado); aliás, é um fenómeno comum às línguas românicas ocidentais e cujos primeiros traços já se encontram no latim vulgar do século II (cf. p.ex. Williams 1938: 6, 65; Bourciez 1946: 48; Battisti 1949: 117; Grandgent 1970: 154-155);

- /a/- protético nalguns advérbios: lat. $i b \bar{\imath}>$ ant.pt. $y$, $h y>$ pt. aí.

No primeiro caso, a mudança ocorreu no intuito de facilitar a pronúncia. No segundo, deve ter havido ação de analogia a outros advérbios, como aqui (< lat. eccu hīc), acá - hoje cá

1 Apesar de se referir muitas vezes apenas às formações lexicais recentes, no presente trabalho, o termo neologismo é empregado no sentido lato de 'nova palavra', abrangendo tanto os vocábulos formados através de processos morfológicos (derivação e composição), como os empréstimos (cf. Villalva \& Silvestre 2014: 72). 
(< lat. eccu hāc), acolá (< lat. eccu illāc), ali (< lat. ad illīc), alá - hoje lá (< lat. ad illāc), bem como pronomes demonstrativos (cf. Williams 1938: 112; Huber 1986: 69); para o desenvolvimento da vogal protética também pode ter contribuído a ênfase que os locutores deram ao advérbio para reforçar o seu valor deítico.

Quanto à aférese, parece não haver regularidades (cf. Williams 1938: 102), mas citem-se também alguns exemplos: lat. erīciu- > pt. riço ${ }^{2}$; lat. ${ }^{*}$ opāciu- > pt. baço (adj.); lat. eclipse- > pt. cris; fr. étalon > pt. talão.

Os casos homólogos de prótese e aférese, nos quais participam os artigos, analisar-se-ão em seguida.

\section{Análise}

O corpus foi constituído sobretudo a partir do Dicionário etimológico da língua portuguesa de Antônio Geraldo da Cunha, do qual, aquando da leitura, fomos extraindo as palavras resultando de um dos processos que nos interessam. Em seguida, o corpus foi verificado e completado durante a consulta de outros dicionários etimológicos (Machado 1952; Nascentes 1955 e REW) e trabalhos de linguística histórica do português (Vasconcelos 1911, 1928 e 1961; Coutinho 1962; Nunes 1975; Williams 1938; Huber 1986). Apoiámo-nos igualmente em estudos de linguística histórica românica (sobretudo Bourciez 1946 e Lausberg 1981).

Dado que se trata de sintagmas nominais com artigos (como fonte ou resultado dos processos em causa), os vocábulos analisados limitam-se forçosamente à classe dos substantivos, seja no singular, seja no plural. Considerámos as palavras do antigo fundo latino, bem como aquelas de importação estrangeira que entraram no léxico português nas épocas posteriores - mas excluindo os arabismos, em que a presença do artigo definido incorporado é um fenómeno transparente.

Os processos considerados interessam-nos do ponto de vista da sua vitalidade e persistência, no sentido em que os seus resultados continuam presentes no léxico contemporâneo. Por conseguinte, omitem-se os substantivos que no passado foram atestados sob formas refletindo incorporação e separação do artigo, mas hoje só têm formas isentas desses fenómenos, como p.ex.: lat. diceta $>$ fr. diète > pt. dieta / adieta (séc. XVI), hoje só dieta; neerl. dijc > ant.fr. dique > pt. dique / adique (séc. XVI), hoje só dique. Também se excluem os substantivos com incorporação ou separação do artigo que tinha ocorrido antes da chegada destes ao português: pt. abessana $<$ esp. abesana / besana < lat. * versāna-. Além disso, omitem-se os casos em que não é possível estabelecer se a forma primitiva tinha ou não a vogal inicial: p.ex. varga, no século XV avarga, tem uma origem pré-romana não documentada, se calhar céltica.

Constituindo o corpus, foi preciso distinguirmos os casos de deglutinação e aglutinação do artigo de processos diferentes, mas cujos resultados se assemelham. Assim, rejeitámos os substantivos:

2 Silva Neto (1952: 137) acrescenta aqui o substantivo ouriço, sugerindo o seguinte: "A mim parece que, depois da aférese do e-riço, se deu a aglutinação do artigo (o-riço)". No entanto, a nosso ver, esta hipótese não é verosímil. 
- deverbais, como: arrasto < arrastar (e não < rasto);

- derivados pelo prefixo $a$ - (< lat. $a d$-), seja em português, seja ainda em latim, como: arredor < redor; anotação < lat. adnotātiō (e não < notação); aventura < fr. aventure < lat. adventūra (e não $<$ ventura < lat. ventūra) (cf. Williams 1938: 112);

- que desenvolveram um $a$ - inicial por causa da pronúncia forte do $r$ - e onde não se pode tratar da incorporação do artigo pela falta de concordância com o género gramatical, p.ex. arruído < ruído (cf. Huber 1986: 155).

\subsection{Substantivo $1>$ artigo + substantivo 2}

O primeiro tipo de fenómeno analisado consistiu numa disjunção do $a$ - ou do $o$ - inicial do substantivo, por serem consideradas essas vogais como artigos definidos (esquematicamente: substantivo $1>$ artigo + substantivo 2 ). Incluem-se neste grupo as seguintes palavras ${ }^{3}$ :

\begin{tabular}{|c|c|c|c|}
\hline & etimologia & forma completa & forma com artigo deglutinado \\
\hline 1. & lat. ${ }^{*}$ avis tarda $\mathrm{f}$. & abetarda f. (XIII) & batarda $\mathrm{f}$. \\
\hline 2. & lat. vg. abbātīna $\mathrm{f}$. & abatina f. (antiquado, XVIII) & batina f. (XVIII) \\
\hline 3. & gr. epískopos > lat. episcopus m. & obispo m. (XIV) & bispo m. (XIII) \\
\hline 4. & lat. habitācula n.pl. & - & bitácula f. (XIX) \\
\hline 5. & gr. apothékēe > lat. apothēca f. & - & bodega f. (XIII) \\
\hline 6. & lat. occāsio, occāsiōnis f. & $\begin{array}{l}\text { ocajon, oqueijon, etc. (XIII), } \\
\underline{\text { ocasião f. (cultismo) }}\end{array}$ & cajão m. (XIII) \\
\hline 7. & $\begin{array}{l}\text { lat. aquimināle, aquimanìle > } \\
\text { *aquiminīle } \mathrm{n} \text {. }\end{array}$ & agomil m. (XIV) & gomil m. (XVI) \\
\hline 8. & lat. acūmen $\mathrm{n}$. & - & gume m. (XVI) \\
\hline 9. & lat. adligāre > pt. aliar & aliança f. (XV) & liança f. (XIV) \\
\hline 10. & fr. Olonne (topónimo) & - & lona f. (XV) \\
\hline 11. & $\begin{array}{l}\text { gr. alóē oxines > lat. tard. } \\
\text { aloxina f. }\end{array}$ & alosna f. (XIV) & losna f. (XIV) \\
\hline 12. & taino hamaca > esp. hamaca f. & - & maca f. (XIX) \\
\hline 13. & prov. homenatge $\mathrm{m}$. & homenagem m. / f. (XIV) & menagem $\mathrm{f}$. (antiquado, XIII) \\
\hline 14. & lat. uрира f. & - & poupa f. (XVI) \\
\hline 15. & lat. hörologium n. & - & relógio $\mathrm{m} .(\mathrm{XV})$ \\
\hline 16. & lat. horror, horrōris $\mathrm{m}$. & horror m. (cultismo) (XVII) & ror $\mathrm{m}$. (informal) \\
\hline 17. & lat. alūmen $\mathrm{n}$. & $\begin{array}{l}\text { ahume (XIV), alúmen } \mathrm{m} . \\
\text { (cultismo) }\end{array}$ & ume m. (XV) \\
\hline
\end{tabular}

3 As palavras sublinhadas continuam a funcionar no léxico contemporâneo. Sempre que possível, indica-se entre parênteses o século em que aparece a primeira abonação da palavra em questão. 


\begin{tabular}{|c|c|c|c|}
\hline & etimologia & forma completa & forma com artigo deglutinado \\
\hline 18. & fr. avant-garde f. & avanguarda f. (XV) & vanguarda $\mathrm{f} .(\mathrm{XV})$ \\
\hline 19. & fr. avantage $\mathrm{m}$. & $\begin{array}{l}\text { avãtajem, aavantage, etc. m. / } \\
\text { f. (XIV) }\end{array}$ & vantagem $\mathrm{f} .(\mathrm{XV})$ \\
\hline 20. & lat. tard. abante prep. & avante prep. (XIII) & vante f. (XVI) \\
\hline 21. & pt. Ovar (topónimo) & - & vareiro $\mathrm{m}$. \\
\hline 22. & & ovarino $\mathrm{m}$. & varino $\mathrm{m}$. \\
\hline 23. & lat. ossifragus $\mathrm{m}$. & - & xofrango m. (XIX) \\
\hline
\end{tabular}

Em todos os vocábulos enumerados na última coluna observa-se uma aférese da vogal inicial, ou melhor, uma reinterpretação no sentido de se separar a vogal inicial considerada como artigo e criação de um novo substantivo. Na maior parte dos casos (13 / 23, ou seja 57\%) cortou-se o suposto artigo feminino, e o masculino em 43\% dos casos (10 / 23). Alguns exemplos indicam diretamente que a reinterpretação ocorreu a partir da forma sonora e não escrita, uma vez que desapareceu também a letra $<\mathrm{h}>$ etimológica não pronunciada (maca, menagem, ror).

Observe-se nesta ocasião uma instabilidade do género gramatical dos neologismos. A mudança ocorre ora em função do género gramatical sugerido pelo novo "artigo", ora de acordo com a terminação da palavra. Os textos antigos ${ }^{4}$ revelam essa instabilidade, p.ex.:

- cajão: "Pero cõvem que tragamos nossa fazenda con siso, ca em outra maneira muy toste poderiamos prender muy maao cajon." / "E sobr'esto entrou antr'elles tal contenda por que depois ouverõ muytas lides os de Crasto con os de Lara e ouve hy muytos mortos, de guisa que se ouvera de perder o reyno por esta cajon." (Crónica Geral de Espanha de 1344);

- gume: "[...] te daua ele co a espada chaa e tu destelhe co a gume ca nõ tomaste a doutrina da perfeiçõ de Christo [...]" (Tratado de confissom, 1489) / "E cada uma déstas ármas é neçessário que tenha dous gumes, cá, sem eles, serám como férro morto. A um gume chamam espírito, e ao outro constância." (João de Barros, Gramática da língua portuguesa, 1540).

\subsection{Artigo + substantivo $1>$ substantivo 2}

Verifica-se igualmente a direção inversa do processo, ou seja, o artigo inteiro (ou uma parte dele, no caso do único artigo indefinido dissilábico uma) junta-se ao substantivo (portanto: artigo + substantivo $1>$ substantivo 2). Este grupo inclui as seguintes palavras:

\begin{tabular}{|r|l|l|l|}
\hline \multicolumn{1}{|c|}{ etimologia } & \multicolumn{1}{c|}{ forma sem artigo } & \multicolumn{1}{c|}{ forma com artigo aglutinado } \\
\hline 1. & it. baderna $\mathrm{f}$. & $\underline{\text { baderna } \mathrm{f} .(\mathrm{XVIII})}$ & abaderna $\mathrm{f}$. (XVIII) \\
\hline 2. & gr. phántasma $>$ lat. phantasma n. & fantasma $\mathrm{m}$. (cultismo, XIV) & $\begin{array}{l}\text { abantesma, abentesma, avantesma, } \\
\text { aventesma } \mathrm{m} . / \mathrm{f} \text {. (informal, XVI) }\end{array}$ \\
\hline 3. & ant. escandinavo biti $>$ fr. bitte f. & - & abita $\mathrm{f} .(\mathrm{XVI})$ \\
\hline
\end{tabular}

4 Todas as citações provêm do Corpus do Português. 


\begin{tabular}{|c|c|c|c|}
\hline & etimologia & forma sem artigo & forma com artigo aglutinado \\
\hline 4. & lat. volvita $\mathrm{f}$. & boveda f. (XV) & abóbada f. (XIV) \\
\hline 5 & it. drizza f. & driça f. (XVI) & adriça f. (XV) \\
\hline 6. & fr. douelle f. & duella f. (XV) & aduela $\mathrm{f} .(\mathrm{XV})$ \\
\hline 7. & lat. lanterna $\mathrm{f}$. & lanterna f. (XIII) & alanterna f. (antiquado) \\
\hline 8. & lat. loesio, loesiōnis f. & $\begin{array}{l}\text { lijon, lissõ, etc. (XIII), lesão f. } \\
\text { (cultismo) }\end{array}$ & aleijão m. (XV) \\
\hline 9. & lat. minācia $\mathrm{f}$. & meaça f. (XIII) & ameaça f. (XIV) \\
\hline 10. & lat. mina $\mathrm{f}$. & - & ameia f. (XIII) \\
\hline 11. & $\begin{array}{l}\text { gr. mýxa }>\text { lat. myxa }>^{*} \text { myxila } \\
/^{\star} \text { myxula f. }\end{array}$ & - & ameixa $^{\mathrm{A}}$ f. (XVI) \\
\hline 12. & lat. medietās, medietātis $\mathrm{f}$. & metade f. (XIII) & ametade f. (XIII) \\
\hline 13. & lat. vulg. mōra f. & - & amora f. (XVI) \\
\hline 14. & pt. linhagem $>^{*}$ niagem $\mathrm{f}$. & - & aniagem $\mathrm{f}$. (XVIII) \\
\hline 15. & lat.pedānea f. & peanha f. (XVI) & apeanha $\mathrm{f}$. \\
\hline 16. & lat. raia f. & raia f. (XVI) & arraia f. (XV) \\
\hline 17. & \multirow[t]{2}{*}{ lat. rāna f. } & \multirow[t]{2}{*}{$\underline{r a \tilde{f} f .}(\mathrm{XIII})$} & arrã f. (popular) \\
\hline 18. & & & marrã f. (dial.) \\
\hline 19. & lat. rīpa f. & riba f. (XIII) & arriba f. (XIII) \\
\hline 20. & fr. ride $\mathrm{f}$. & - & arrida f. (XIX) \\
\hline 21. & lat. ${ }^{*}$ radiola $\mathrm{f}$. & - & arrió, arriós, arriol m. $(\mathrm{XVI})^{\mathrm{B}}$ \\
\hline 22. & lat. rūta f. & - & arruda f. (XIV) \\
\hline 23. & lat. tard. rotella $>$ ant.fr. roelle $\mathrm{f}$. & rroela f. (XIV) & arruela $\mathrm{f} . \mathrm{XV})$ \\
\hline 24. & lat. vīsio, vīsiōnis $\mathrm{f}$. & $\begin{array}{l}\text { vison, vision (XIII), visão } \mathrm{f} . \\
\text { (cultismo) }\end{array}$ & avejão m. (XVII) \\
\hline 25. & lat. vinca $\mathrm{f}$. & - & avenca f. (XVI) \\
\hline 26. & \multirow[t]{2}{*}{ lat. *tēlāria > pt. teira f. } & \multirow[t]{2}{*}{ teiró f. $(\mathrm{XVII})^{\mathrm{C}}$} & ateiró $\mathrm{m}$. \\
\hline 27. & & & mateiró m. (dial.) \\
\hline 28. & lat. lucta f. & luta f. (XIII) & maluta f. (dial.) ${ }^{\mathrm{D}}$ \\
\hline 29. & $?$ & reca f. (dial.) & marreca f. (dial.) \\
\hline 30. & lat. ${ }^{\star}$ lïbellus $\mathrm{m}$. & nível, livel, ambos m. (XVI) & olivel m. (XVI) \\
\hline 31. & cat. orat $\mathrm{m} .>$ esp. orate m. / f. & orate $\mathrm{m} . / \mathrm{f} .(\mathrm{XVII})$ & zorate $\mathrm{m} . /$ f., zorato $\mathrm{m}^{\mathrm{E}}$ \\
\hline
\end{tabular}

A É uma das hipóteses etimológicas existentes. Outra diz que o nome vem do lat. ${ }^{\star}$ damasina $>$ pt. ${ }^{*}$ dameixia $>$ de amei$x i a$ (deglutinação da preposição) > ameixia > ameixa. O termo teria substituído o adjetivo latino damascēna '(ameixa) de Damasco', por sua vez emprestado ao grego.

B Cf. Dębowiak (2013: 135).

C Cf. Dębowiak (2013: 144).

D Cf. Vasconcelos (1911: 63)

E Cf. Vasconcelos (1911: 63). 
Vê-se nas palavras da última coluna a adjunção de [o]-, [r]-, [me]- e [z]- iniciais, originalmente artigos ou partes deles, considerados secundariamente como elemento integrante do substantivo. Prevalece decididamente a fusão do artigo feminino: o artigo definido $a$ aparece em 81\% dos casos (25 / 31 palavras), a sílaba -ma do indefinido em 13\% (4 / 31). O artigo masculino tem uma representação muito fraca, apenas 3\% (1/31), e os mesmos números respeitam ao $-s$ do artigo definido no plural.

Neste grupo também se verifica uma instabilidade do género gramatical das palavras, testemunhada pelas abonações em textos. Sirvam de exemplo dois vocábulos:

- aleijão: "Ele faz o vil nobre, o feio belo; ele desfaz a aleijao e a desformidade." (Francisco Manuel de Melo, Apólogos dialogais, séc. XVII) / “[...] com umas correias atei a perna direita por baixo dos calçoes a outra que pus na cintura e, ficando enfreada, parecia que tinha os nervos encolhidos e que deles me nascia aquele aleijao." (Gaspar Pires Ribelo, Infortunios trágicos da constante Florinda, séc. XVII);

- abantesma: "À beira das eleições próximas, essa abantesma da ruína da lavoura pela emancipação, depois das enérgicas palavras do eminente Sr. de Cotegipe, não induz a pensar na invenção escocesa?" (Rui Barbosa, Obras seletas, séc. XIX) / "Ao ver-me todo ataviado para a guerra, Pero Lopes Gedeão assombrou-se, tal tivesse visto um abantesma, e a face se lhe empalideceu e quase perdeu ele os sentidos." (Álvaro Cardoso Gomes, Os Rios Inumeráveis, 1997).

\section{Conclusão}

Antes de concluir, importa assinalarmos um problema terminológico. Os processos em questão foram estudados à parte, como fenómenos separados, muito raramente em obras de linguística portuguesa ${ }^{5}$. Assim sendo, eles não possuem nomes específicos estáveis nos trabalhos linguísticos. A título de exemplo, Leite de Vasconcelos (1911: 63; 1928: 399; 1961: 220) emprega termos como disjunção, deglutinação, coalescência, mas sem ser consequente. Nunes (1975: 59, 257-258) diz tratar-se de fusão ou aglutinação e desaparecimento ou deglutinação do artigo. Por sua vez, Huber $(1986: 72,76)$ fala da separação ou queda da vogal inicial. A fim de unificar a terminologia, inclinar-nos-íamos a valorizar os termos deglutinação e aglutinação, operando em sintagmas nominais que contêm artigos. Parecem-nos designações mais adequadas para os processos analisados no presente estudo.

Do ponto de vista da variação lexical, é de frisar que embora no corpus se registem alguns vocábulos antiquados (alanterna, menagem), dialetais (maluta, marrã, marreca) ou próprios do registo familiar (abantesma, ror), a maior parte deles pertence ao léxico do português-padrão.

Em termos quantitativos, a partir do corpus estudado verifica-se que a aglutinação do artigo é um fenómeno mais frequente do que a deglutinação: são 31 versus 23 vocábulos, ou seja, $57 \%$ de todos os exemplos registados resultam de aglutinação.

5 José Leite de Vasconcelos (1898: 423-426) trata especificamente do fenómeno em questão, mas lamentavelmente não tivemos acesso a este trabalho. Dispomos dessa informação graças à referência que se encontra num outro texto do mesmo autor (Vasconcelos 1911: 62). 
A manutenção de ambas as formas divergentes ocorre mais ou menos na metade dos exemplos analisados:

- original e com deglutinação: 11 / 23 vocábulos (48\%);

- original e com aglutinação: 17 / 31 vocábulos (55\%).

Quanto à morfologia, observe-se uma mudança do género gramatical do substantivo de base depois de se ter manifestado um dos dois processos:

- com deglutinação: 1 / 23 vocábulos (4\%);

- com aglutinação: 4 / 31 vocábulos (13\%).

No que toca à semântica, apresentamos conclusões com base em neologismos que coexistem ao lado de substantivos originais. Os dados incluem-se na seguinte tabela:

\begin{tabular}{|l|l|l|c|}
\hline \multicolumn{1}{|c|}{ substantivo } & \multicolumn{1}{|c|}{ sinonímia parcial ou completa } & \multicolumn{1}{c|}{ especialização semântica } & total \\
\hline com deglutinação & $\begin{array}{l}\text { batarda, batina, cajão, gomil, liança, } \\
\text { losna, menagem, ume, varino }\end{array}$ & ror, vante & 11 \\
\hline com aglutinação & $\begin{array}{l}\text { abantesma, alanterna, ametade, } \\
\text { apeanha, arraia, arrã, arriba, ateiró, } \\
\text { mateiró, maluta, olivel, } \text {,orate }\end{array}$ & $\begin{array}{l}\text { abaderna, aleijão, avejão, marrãa, } \\
\text { marreca }\end{array}$ & 17 \\
\hline total & 21 & 7 & 28 \\
\hline
\end{tabular}

No total, 21 / 28 vocábulos (75\%) são sinónimos parciais ou completos dos substantivos que se conservaram sem mudança. A sinonímia ocorre mais frequentemente nas palavras que sofreram deglutinação $(9 / 11$, ou seja $82 \%)$ do que naquelas que testemunham aglutinação (12 / 17, ou seja 71\%). A especialização semântica dos neologismos é um fenómeno mais raro, apresentando-se apenas em 25\% (7 / 28) de todos os casos registados. Desta vez, a ocorrência é mais frequente nas palavras resultantes de aglutinação (5 / 17, isto é 29\%) do que naquelas que sofreram deglutinação (2 / 11, isto é 18\%). Depreende-se daí que a aglutinação do artigo tende ligeiramente a individualizar o novo substantivo, ao passo que a deglutinação de um suposto artigo costuma não influenciar tanto a semântica das palavras.

Os dados numéricos expostos acima provam que, embora presentes em várias épocas, ambos os processos tidos em conta foram e são pouco produtivos, tanto do ponto de vista morfológico, como semântico, com uma contribuição insignificante para o enriquecimento do léxico português. Esta conclusão parece lógica se se olhar numa perspetiva de leis fonéticas: tais desenvolvimentos não são situações dominantes porque constituem um desvio da regra geral segundo a qual /a/- e /o/- iniciais átonas costumam manter-se em português (cf. Huber 1986: 69, 77)6.

Quais são portanto as causas possíveis da deglutinação e aglutinação do artigo, por mais raramente que tenham acontecido? Poder-se-iam propor várias explicações, algumas das quais

6 Confiram-se os seguintes exemplos: lat. acētu- > pt. azedo; lat. acūtu- > pt. agudo; lat. amāre > pt. amar; lat. hora- > pt. ora; lat. hoc anno > ant.pt. ogano; lat. öräre > pt. orar. 
já se encontram nos trabalhos que consultámos. A mais extensa é aquela dada por Leite de Vasconcelos (e repetida por Nunes 1975: 58):

A grande tenuidade do artigo, sobretudo do definido, faz que ele se encorpore facilmente noutras palavras [...]. Ao mesmo tempo que o artigo pode aglutinar-se à palavra a que se refere, pode também suceder que, começando certas palavras por $o$, este som desapareça (deglutinação), por se confundir com o artigo [...]. Com relação a nomes femininos, deve haver oscilações semelhantes, mas aí a averiguação torna-se mais difícil, porque a adição ou a supressão de $a$ podem ser fenómenos meramente fonéticos (prótese e aférese), e não estamos sempre no caso de distinguir se, quando elas se manifestam, isso se deve a causas fisiológicas [prótese e aférese] ou psicológicas [aglutinação e deglutinação do artigo]. (Vasconcelos 1911: 62-64, com ortografia atualizada).

Uma confusão da vogal inicial com o artigo definido também é mencionada por Williams (1938: 103) e nalguns artigos nos dicionários etimológicos consultados (p.ex. Cunha 2012 s.v. ameaça, ameixa, amora, aniagem, cajão, maca, menagem, ocasião).

Portanto, a confusão de uma parte da palavra com um artigo é a causa mais saliente. Às vezes pode ter ocorrido uma aférese ou prótese espontânea, favorecida por vários fatores, como a existência do prefixo $a$ - (< lat. $a d$-) na língua portuguesa. Há também uma explicação fonética para as palavras que originalmente começavam com /r/-: neste caso é possível surgir um /a/protético de apoio, fenómeno já mencionado e que tem paralelo em outras línguas românicas: megleno-romeno, romanche e gascão (cf. Bourciez 1946: 302, 560, 612). Finalmente, é possível uma analogia às palavras de origem árabe em que o artigo definido original $a$ - (variante contextual de al-) é capaz de ser instável, cf. arrecife / recife, arrécova / récova, atambor / tambor, adarga / darga, etc. Prova-o a documentação de casos homólogos de origem latina: almea (séc. XIV) por ameia, almeixa (séc. XVI) por ameixa, etc.

Por fim, diga-se que os fenómenos em questão operaram numa escala mais alargada, tendo ocorrido na onomástica portuguesa e nos crioulos de base portuguesa (cf. Vasconcelos 1928: 399-402). Encontram-se igualmente situações paralelas românicas, p.ex. it. larena > it. la rena 'areia', fr. l'ierre > lierre 'hera', l'agriotte > la griotte 'ginja' (Bourciez 1946: 156; Bochnakowa 1997 e 1999), bem como de outras famílias de línguas que conhecem o artigo anteposto, p.ex. alemão ein Nackt > ein Ackt 'nu artístico' (Mańczak 1997), inglês a nadder > an adder 'víbora'.

Resumindo, para a deglutinação e aglutinação do artigo contribuíram alguns fenómenos entrelaçados, o que faz com que seja difícil considerá-los independentemente. Os processos analisados inscreveram-se nas tendências do desenvolvimento lexical já existentes em latim e também nas línguas românicas, tendo provavelmente influenciado a evolução de outras palavras, sem no entanto funcionarem isoladamente como unidade produtiva. 


\section{Referências bibliográficas}

Battisti, C. (1949). Avviamento allo studio del latino volgare. Bari: Leonardo da Vinci Editrice.

Bochnakowa, A. (1997). Fausse démarcation comme source de néologismes. Revue des Langues Romanes, CI, 1, 37-44.

- (1999). Origine de quelques mots romans ou effets de l'agglutination et de la déglutination. Studia Etymologica Cracoviensia, 4, 41-46.

Bourciez, É. (1946). Éléments de linguistique romane (édition révisée par l’auteur et par les soins de Jean Bourciez; quatrième édition). Paris: Librairie C. Klincksieck.

Coutinho, I. de Lima (1962). Pontos de Gramática Histórica (5. ${ }^{a}$ edição revista e aumentada). Rio de Janeiro: Livraria Acadêmica.

Cunha, A. G. da (2012). Dicionário etimológico da língua portuguesa (4a edição revista e atualizada, $3^{\mathrm{a}}$ impressão). Rio de Janeiro: Lexicon.

Dębowiak, P. (2013). Nota de morfologia histórica do português: sufixo *-ó. Diacrítica. Série Ciências da Linguagem, 27, 1, 131-152.

Grandgent, Ch. Hall (1970). Introducción al latín vulgar (4. ${ }^{a}$ edición, traducción y anotación por Francisco de B. Moll). Madrid: Consejo Superior de Investigaciones Científicas.

Huber, J. (1986). Gramática do português antigo (Tradução de Maria Manuela Gouveia Delille). Lisboa: Fundação Calouste Gulbenkian.

Lausberg, H. (1981). Linguística românica (tradução de Marion Ehrhardt e Maria Luísa Schemann; 2. edição). Lisboa: Fundação Calouste Gulbenkian.

Machado, J. P. (1952). Dicionário etimológico da língua portuguesa. 2 vol. Lisboa: Horizonte.

Mańczak, W. (1997). Étymologie de l'allemand Akt 'nu'. Studia Etymologica Cracoviensia, 2, 173-174.

Nascentes, A. (1955). Dicionário etimológico da língua portuguesa. 2 vol. Rio de Janeiro: Oficinas gráficas do "Jornal do Commercio".

Nunes, J. J. (1975). Compêndio de gramática histórica portuguesa. Fonética e morfologia (8. edição). Lisboa: Livraria Clássica Editora.

REW = Meyer-Lübke, W. (1930-1935). Romanisches Etymologisches Wörterbuch. Heidelberg: Winter.

Silva Neto, S. (1952). Manual de Filologia Portuguesa. História. Problemas. Métodos. Rio de Janeiro: Livraria Acadêmica.

Vasconcelos, J. Leite de (1898). Notas philologicas. II. Revue hispanique, 16, 5, 417-429.

— . (1911). Lições de Philologia Portuguesa. Lisboa: Livraria Clássica Editora de A. M. Teixeira \& C. TA

_. (1928). Opúsculos. Volume I. Filologia. Parte I. Coimbra: Imprensa da Universidade.

- (1961). Estudos de filologia portuguesa. Rio de Janeiro: Livros de Portugal.

Villalva, A. (2003). Formação de palavras: composição. In M. H. Mira Mateus et al. (Eds.), Gramática da Língua Portuguesa (7. a edição) (pp. 969-983). Lisboa: Caminho.

Villalva, A., \& Silvestre, J. P. (2014). Introdução ao estudo do léxico. Petrópolis: Vozes.

Williams, E. B. (1938). From Latin to Portuguese. Philadelphia: University of Pennsylvania Press.

\section{Páginas web}

Corpus do Português: http://www.corpusdoportugues.org/ [última consulta: 12/02/2016]. 